\title{
LUNG MECHANICAL CHANGES FOLLOWING BRONCHOASPIRATION IN A PORCINE MODEL: DIFFERENTIATION OF DIRECT AND INDIRECT MECHANISMS
}

\author{
Gergely H. Fodor, MD ${ }^{1}$, Ferenc Peták, PhD ${ }^{1}$, Dániel Érces, MD ${ }^{2}$, Ádám L. Balogh ${ }^{3}$, \\ Barna Babik, $\mathrm{MD}, \mathrm{PhD}^{3}$
}

${ }^{1}$ Department of Physics and Informatics, University of Szeged, Szeged, Hungary

${ }^{2}$ Institute of Surgical Research, University of Szeged, Szeged, Hungary

${ }^{3}$ Department of Anaesthesiology and Intensive Therapy, University of Szeged, Szeged, Hungary

Address for correspondence:

Ferenc Peták

Department of Medical Physics and Informatics

University of Szeged

Korányi fasor 9.

H-6720 Szeged, Hungary

Fax: +36 62545077

Phone: +36 62544566

e-mail: petak.ferenc@med.u-szeged.hu

Running head: Unilateral bronchoaspiration and changes in lung function 


\begin{abstract}
Bronchoaspiration results in local deterioration of lung function through direct damage and/or indirect systemic effects related to neurohumoral pathways. We distinguished these effects by selectively intubating the two main bronchi in pigs while a PEEP of 4 or $10 \mathrm{cmH}_{2} \mathrm{O}$ was maintained. Gastric juice was instilled only into the right lung. Lung mechanical and ventilation defects were assessed by measuring unilateral pulmonary input impedance $\left(\mathrm{Z}_{\mathrm{L}, \mathrm{s}}\right)$ and the third phase slope of the capnogram $\left(\mathrm{S}_{\mathrm{III}}\right)$ for each lung side separately before the aspiration and for 120 min thereafter. Marked transient elevations in $\mathrm{Z}_{\mathrm{L}, \mathrm{s}}$ parameters and $\mathrm{S}_{\mathrm{III}}$ were observed in the affected lung after aspiration. Elevating PEEP did not affect these responses in the $\mathrm{Z}_{\mathrm{L}, \mathrm{s}}$ parameters, whereas it prevented the $\mathrm{S}_{\mathrm{III}}$ increases. None of these indices changed in the intact left lung. These findings furnish evidence of the predominance of the local direct damage over the indirect systemic effects in the development of the deterioration of lung function, and demonstrate the benefit of an initially elevated PEEP following aspiration.
\end{abstract}




\section{INTRODUCTION}

Management of the adverse pulmonary consequences of bronchoaspiration poses a major challenge for health professionals during general anaesthesia and intensive care (Marik, 2001, 2011). This syndrome has been reported to cause a high incidence of morbidity and mortality, involving up to $90 \%$ of the affected patients, depending on the extent of the involved lung regions (Cameron et al., 1973; Engelhardt and Webster, 1999; LeFrock et al., 1979; Olsson et al., 1986; Warner et al., 1993). Inhalation of the gastric contents into the lower respiratory tract induces a number of pulmonary syndromes, described originally by Mendelson et al., including acute aspiration pneumonitis caused by the acidity subsequent to chemical injury (Mendelson, 1946), and aspiration pneumonia resulting from the inhalation of pathogenic bacteria (Marik, 2001, 2011; Raghavendran et al., 2011).

The mechanisms responsible for the acute deterioration of lung function following aspiration of the gastric contents have not been fully clarified. Earlier results demonstrated the involvement of direct physiochemical processes leading to mucosal damage and desquamation (Kennedy et al., 1989; Wynne et al., 1981). Another direct effect of gastric juice aspiration may be related to pepsin being cytotoxic to bronchial epithelial cells (Bathoorn et al., 2011). A further direct mechanism of lung injury following bronchoaspiration may be subsequent to the induced surfactant dysfunction (Lamonica et al., 2014). Besides these direct mechanisms, indirect pathways have also been reported to be involved in the course of aspiration, since the lung injury has been found to be mediated by capsaicin-sensitive vagal sensory afferent nerves (Kennedy et al., 1989; Kollarik et al., 2007; Martling and Lundberg, 1988; Nemzek and Kim, 2009). Another indirect route may be due to the activation of systemic inflammatory processes originating from the affected lungs, 
including the release of endogenous mediators by neutrophils, alveolar macrophages or by activation of the complement system leading to vascular leakage and oedema formation (Goldman et al., 1991; Kennedy et al., 1989; Knight et al., 1992; Nader-Djalal et al., 2007; Nishizawa et al., 1996; Weiser et al., 1997). Although the effective prevention and/or treatment of the bronchoaspiration would require the identification of the roles of these individual mechanisms, no previous studies have attempted to clarify the involvement of the direct and indirect pathways in the adverse functional changes in the lung during the acute phase of gastric juice inhalation.

Another important factor that may affect the severity of the lung damage and the outcome of bronchoaspiration is the application of a raised positive end-expiratory pressure (PEEP). While an elevated PEEP is beneficial for the recruitment of lung regions and maintaining them open during mechanical ventilation (Colmenero-Ruiz et al., 1997; Ko et al., 2008), a significant hemodynamic impairment characterized by a deterioration in cardiac function may also occur during a PEEP increment (Marumo et al., 2009).

The aims of the present study were therefore to quantify the separate roles of direct and indirect mechanisms of the deterioration of lung mechanics following acid aspiration. Acidic gastric content was unilaterally administered into one lung and changes of lung mechanics were measured alternately in the affected and intact lungs. A further aim was to investigate the effects of different PEEP levels on the respiratory and circulatory outcomes during and following the inhalation of gastric juice. 


\section{MATERIALS AND METHODS}

The work was carried out in accordance with EU Directive 2010/63/EU relating to animal experiments. The experimental protocol was approved by the institutional Animal Care Committee of the Faculty of Medicine at the University of Szeged, (No. XIV/152/2013), and was performed in accordance with the National Institutes of Health guidelines for animal use.

\subsection{Animal preparations}

Male Vietnamese mini-pigs ( $\mathrm{n}=13)$ weighing $28.2 \pm 0.9 \mathrm{~kg}(21-33 \mathrm{~kg})$ were used in the present study. Anaesthesia was induced by an intramuscular injection of ketamine $(20 \mathrm{mg} / \mathrm{kg}$, CPKetamin $10 \%$, Produlab Pharma, Raamsdonksveer, Netherlands) and xylazine (2 mg/kg, CPXylazin $2 \%$, Produlab Pharma, Raamsdonksveer, Netherlands) until an i.v. line was secured into the ear. A continuous infusion of propofol $(6 \mathrm{mg} / \mathrm{kg} / \mathrm{h}$, Propofol $2 \% \mathrm{MCT} / \mathrm{LCT}$, Fresenius-Kabi, Bad Homburg, Germany) was then maintained throughout the study via the ear vein. The mini-pigs were tracheostomized and a double-lumen cannula (Broncho-cath right 35 Fr, Mallinckrodt Medical, Athlone, Ireland) was introduced into the distal trachea. The double lumen tracheostomy tube was positioned to achieve separate support of the left and right lung sides and the tips were sealed by inflating a cuff. The pigs were then mechanically ventilated (Model 900C; Siemens-Elema, Solna, Sweden) in volume-controlled mode with a tidal volume of $7-8 \mathrm{ml} / \mathrm{kg}$ at a frequency of $\sim 20 / \mathrm{min}$ and an inspired oxygen fraction $\left(\mathrm{FiO}_{2}\right)$ of 0.3 in air. A femoral artery was prepared surgically in a sterile manner and cannulated for blood sampling and the measurement of arterial blood pressure and cardiac output by thermodilution (PiCCO Catheters; PULSION Medical Systems, Feldkirchen, Germany). The jugular vein was prepared in the same way as the femoral artery and cannulated for fluid and drug administration. Muscle relaxation was achieved by regular i.v. administration of pipecuronium $(0.1 \mathrm{mg} / \mathrm{kg}$, every $30 \mathrm{~min}$, Arduan, Richter-Gedeon, 
Budapest, Hungary). The thorax was opened by means of a midline thoracotomy following an i.v. bolus of sufentanyl $(25 \mu \mathrm{g} / \mathrm{kg}$, Sufentanil Torrex, Chiesi Pharmaceuticals, Vienna, Austria) and the ribs were widely retracted. Following chest opening, the pigs were randomly assigned to maintain a PEEP of 4 or $10 \mathrm{cmH}_{2} \mathrm{O}$.

Arterial blood samples were analysed radiometrically (Cobas b221; Roche Diagnostics, Basel, Switzerland). The Horowitz quotient (HQ) was calculated as the ratio of the arterial partial pressure of oxygen and $\mathrm{FiO}_{2}$.

A small incision was made in the stomach and 10-20 ml of gastric juice was obtained via a catheter introduced into the stomach. This gastric juice was filtered to remove solid particles. The $\mathrm{pH}$ of the remaining fluid was determined and hydrochloric acid was added to reach a $\mathrm{pH}$ of 2 if needed.

\subsection{Measurement of lung mechanics}

\subsubsection{Forced oscillations}

The measurement system for collection of the input impedance spectra of the right or left lung $\left(\mathrm{Z}_{\mathrm{L}, \mathrm{s}}\right)$ in the mini-pigs was similar to that used previously for the whole lungs (Petak et al., 2006). Briefly, the mechanical ventilation was ceased at end-expiration and the cannula of the measured lung was connected to a loudspeaker-in-box system while the cannula of the other lung was occluded. Thus, during these 8-s long apnoeic periods, the forced oscillatory signal was introduced only to either the left or the right lung. Prior to the measurements, the pressure in the loudspeaker box chambers was set to the level of the PEEP to keep the mean transpulmonary pressure constant. The loudspeaker delivered a computer-generated smallamplitude $\left(< \pm 1 \mathrm{cmH}_{2} \mathrm{O}\right)$ pseudo-random signal in the interval $0.5-21 \mathrm{~Hz}$ through a screen 
pneumotachograph (11 mm ID), which was used to measure the gas flow (V') with a differential pressure transducer (model 33NA002D; ICSensors, Malpitas, CA, USA). An identical pressure transducer was used to measure the pressure in the left or right main bronchi with reference to the atmosphere $\left(\mathrm{P}_{\mathrm{L}, \mathrm{s}}\right)$.

The $\mathrm{P}_{\mathrm{L}, \mathrm{s}}$ and $\mathrm{V}^{\prime}$ signals were low-pass filtered at $25 \mathrm{~Hz}$ and sampled with an analogue-digital board of a microcomputer at a rate of $256 \mathrm{~Hz}$. Fast Fourier transformation with 4-s time windows and $95 \%$ overlapping was used to calculate the unilateral $\mathrm{Z}_{\mathrm{L}, \mathrm{s}}$ spectra $\left(\mathrm{Z}_{\mathrm{L}, \mathrm{s}} \square=\square \mathrm{P}_{\mathrm{L}, \mathrm{s}} / \mathrm{V}^{\prime}\right)$.

\subsubsection{Estimation of airway and parenchymal parameters}

The airway and parenchymal mechanical properties for the individual lungs were separated by fitting a model to the $\mathrm{Z}_{\mathrm{L}, \mathrm{s}}$ spectra by minimizing the differences between the measured and modelled impedance values. The model consisted of an airway compartment containing airway resistance (Raw) and airway inertance (Iaw), and a constant-phase tissue unit (Hantos et al., 1992) characterized by tissue damping $(\mathrm{G})$ and elastance $(\mathrm{H})$ :

$\mathrm{Z}_{\mathrm{L}, \mathrm{s}}=\mathrm{Raw}+\mathrm{j} \omega \mathrm{Iaw}+(\mathrm{G}-\mathrm{jH}) / \omega^{\alpha}$ where $\mathrm{j}$ is the imaginary unit, $\omega$ is the angular frequency $(2 \pi f)$, and $\alpha$ is $(2 / \pi) \arctan (H / G)$.

\subsection{Capnography}

Changes in partial $\mathrm{CO}_{2}$ pressure in the exhaled gas during mechanical ventilation were measured with a calibrated sidestream capnometer (Cardiocap II; Datex/Instrumentarium, Helsinki, Finland). $\mathrm{CO}_{2}$ traces were recorded alternately from each lung by closing one lumen of the endotracheal tube, at a time while the tidal volume was decreased by one-third by elevating the ventilation frequency. The 8-s $\mathrm{CO}_{2}$ traces obtained from the aspirated or the 
intact lung were imported into custom-developed signal analysis software. The third phase of the expiratory $\mathrm{CO}_{2}$ curves in each expiration was identified by selecting the $\mathrm{CO}_{2}$ traces from its peak end-tidal value back to $60 \%$ of the total length of its linear temporal change. Linear regression analysis was applied to these phases to obtain slope of the third phase of the expiratory capnogram $\left(\mathrm{S}_{\mathrm{III}}\right)$. $\mathrm{S}_{\mathrm{III}}$ was normalized by dividing each slope by the average values of the corresponding $\mathrm{CO}_{2}$ concentration in the mixed expired gas to obtain normalized time domain third phase slopes $\left(\mathrm{S}_{\mathrm{nIII}}\right)$. Four to six expiratory traces were analysed in each recording.

\subsection{Haemodynamic monitoring}

Systemic haemodynamic parameters were monitored by a transpulmonary arterial thermodilution system (PiCCO; Pulsion Medical System, Munich, Germany). A 4F arterial catheter was inserted into the femoral artery. The thermal indicator bolus was injected into the right atrium via a central venous catheter positioned in the jugular vein. The monitor determined the cardiac index $(\mathrm{CI})$ by normalizing the cardiac output to the body surface area. The same monitoring system was used to measure the mean arterial pressure (MAP) and heart rate (HR).

\subsection{Experimental protocol}

Following stabilization of the pulmonary mechanical and haemodynamic variables after the anaesthesia and the preparation, the pigs were randomly assigned to groups in which the PEEP was set to a level of either 4 (Group P4, $\mathrm{n}=7$ ) or $10 \mathrm{cmH}_{2} \mathrm{O}$ (Group P10, $\left.\mathrm{n}=6\right)$. Two sets of baseline $\mathrm{Z}_{\mathrm{L}, \mathrm{s}}$ recordings were then collected for each lung separately by forced oscillations

(Fig. 1). This was followed by registration of the $\mathrm{CO}_{2}$ traces from each lung separately. Aspiration was achieved by unilaterally instilling the prepared gastric juice mixed with 
hydrochloric acid $(\mathrm{pH} 2)$ into the endobronchial lumen (right lung) of the tracheal tube $(0.5 \mathrm{ml} / \mathrm{kg})$ and leaving the left lung unaffected. To maintain the best possible gas exchange and similarity to a clinical situation, $\mathrm{FiO}_{2}$ was elevated to 1 after injection of the gastric content. Forced oscillatory and capnogram measurements were recorded for each lung alternately at 5, 15, 30, 45 and 60 min following aspiration. To assess the effect of a PEEP change in this period, the level of PEEP was interchanged between the groups (10 to $4 \mathrm{cmH}_{2} \mathrm{O}$ and 4 to $10 \mathrm{cmH}_{2} \mathrm{O}$, respectively) 60 min post-aspiration. Following this PEEP interchange, additional $\mathrm{Z}_{\mathrm{L}, \mathrm{s}}$ and $\mathrm{CO}_{2}$ recordings were collected at 65,75 and 90 min post-aspiration. Finally, PEEP was re-established at the original level and additional measurements were performed at 95, 105 and 120 min post-aspiration. Blood gas samples were analysed and thermodilution measurements were performed at baseline and at 20, 80 and $110 \mathrm{~min}$ postaspiration.

\subsection{Statistical analysis}

The scatters in the parameters were expressed as SE values. The Kolmogorov-Smirnov test was used to test data for normality. Two-way repeated measures mixed model of analysis of variance (ANOVA) with the factors assessment time (control vs. post-aspiration) and lung side (aspirated or intact) was used in both PEEP-based groups to assess the effects of the aspiration of the gastric contents on the lung responsiveness, the slope of the third phase of the capnogram and on haemodynamic parameters. The choice of appropriate covariance structure was on the basis of Akaike information criterion measure. The Holm-Sidak multiple comparison procedure was applied to compare the different conditions (for repeated measures) or lung sides (affected or intact). Correlation analyses between the variables were performed by using Pearson correlation tests. Statistical tests were carried out with the 
SigmaPlot software package (version 12.5, Systat Software, Inc, CA, USA) and SAS (version 9.2, SAS Institute, Cary, NC, USA) with a significance level of $\mathrm{p}<0.05$.

\section{RESULTS}

There was no statistically significant difference between the weights of the pigs in the two protocol groups $(29.6 \pm 1.1$ vs. $26.7 \pm 1.4 \mathrm{~kg}$ for Groups P4 and P10, respectively, $\mathrm{p}=0.125)$. The quality of the fitting of the model to the $\mathrm{Z}_{\mathrm{L}, \mathrm{s}}$ spectra was equally good in each group and experimental condition with mean fitting error of $6.1 \pm 0.12 \%$.

\subsection{Unilateral lung mechanical changes}

Figure 2 demonstrates the temporal changes in the airway and lung tissue forced oscillatory mechanical parameters in both experimental groups for the affected (aspirated) and intact lungs separately. The mechanical changes following aspiration appeared generally greater in Group P4 than in P10. Under the baseline conditions, the mechanical parameters did not exhibit any statistically significant differences between the two lung sides in either experimental group. However, in both groups of pigs, significant differences developed between the two sides following gastric juice aspiration: in Raw (at least $\mathrm{p}<0.018$ and $\mathrm{p}<0.032$ for Groups $\mathrm{P} 4$ and P10, respectively), $\mathrm{G}(\mathrm{p}<0.05, \mathrm{p}<0.05)$ and $\mathrm{H}(\mathrm{p}<0.05$, $\mathrm{p}<0.036)$. The peak of the mechanical deterioration on the aspirated side occurred 5-15 min after the bronchoaspiration, with gradual improvements thereafter. The airway and tissue mechanical parameters for the intact side did not exhibit any significant change throughout the study protocol.

The changes in the lung mechanical parameters relative to their baseline values are depicted in Fig. 3 for characteristic time points in the experiments. On the aspirated side, the airway 
and lung tissue mechanical indices were increased significantly 5 min after the aspiration in both Group P4 ( $\mathrm{p}<0.001, \mathrm{p}=0.001$ and $\mathrm{p}<0.001$ for Raw, $\mathrm{G}$ and $\mathrm{H}$, respectively) and Group P10 $(\mathrm{p}=0.012, \mathrm{p}=0.007$ and $\mathrm{p}<0.001)$. The changes on the aspirated side were greater than those on the intact side 5 min after the aspiration in the pigs in Groups P4 $(\mathrm{p}<0.014)$ and P10 ( $<$ 0.037); significant differences were also apparent later for Raw and $\mathrm{H}$ in Group P4 $(\mathrm{p}<0.008, \mathrm{p}=0.029)$ and for $\mathrm{G}$ and $\mathrm{H}$ in Group P10 $(\mathrm{p}=0.037, \mathrm{p}<0.009)$. Significant recoveries started from $60 \mathrm{~min}$ after the aspiration in all mechanical parameters. Lowering the PEEP to $4 \mathrm{cmH}_{2} \mathrm{O}$ in Group $\mathrm{P} 10$ caused a significant decrease in $\mathrm{H}(\mathrm{p}=0.002)$ on the intact side, whereas elevating the PEEP in Group P4 did not have a major effect on the unilateral lung mechanics. The unilateral lung mechanical parameters for the intact side did not demonstrate any significant adverse change following aspiration; in Group P10, G and H were even decreased on the unaffected side 120 min after aspiration $(\mathrm{p}=0.021, \mathrm{p}=0.022)$.

Since indirect mechanisms are expected to alter primarily the airway tone, the changes in Raw in the two lungs were related to reveal the relationship between the magnitudes of the bronchoconstriction. Figure 4 demonstrates the associations between the aspiration-induced changes in Raw obtained from the intact and aspirated sides for the first $60 \mathrm{~min}$ of the experiment. While fairly systematic elevations were observed in Raw on the aspirated side, the changes on the intact side were highly variable, with the majority of the pigs exhibiting even decrements. Nevertheless, there was a statistically significant correlation between the Raw changes on the aspirated and intact sides $(R=0.41, \mathrm{p}=0.002)$.

\subsection{Changes in the capnogram parameters}

The changes in the absolute and normalized third phase slope of the capnogram are demonstrated in Fig. 5 under baseline conditions and 5, 60, 90 and $120 \mathrm{~min}$ after 
bronchoaspiration. No significant change was detected in $S_{\text {III }}$ in Group P10 throughout the study, whereas $\mathrm{S}_{\mathrm{III}}$ was elevated at 5 min on the aspirated side in Group P4 ( $\left.\mathrm{p}=0.01\right)$, with an apparent recovery at $120 \min (\mathrm{p}=0.044) . \mathrm{Sn}_{\text {III }}$ did not change on the intact side during the study, whereas it was significantly elevated on the aspirated side in both groups 5 min after the aspiration $(\mathrm{p}=0.021$ and $\mathrm{p}=0.001$ for Group P10 and P4, respectively). Changing the PEEP elevated the aspirated-side $\mathrm{Sn}_{\mathrm{III}}$ in the pigs of Group P10 $(\mathrm{p}=0.007)$, while there was no change in the intact side in the pigs of Group P10, or on either side in Group P4.

\subsection{Haemodynamic changes}

Under the baseline conditions, CI and HR did not differ between the protocol groups, while the MAP in Group P10 was lower than that in Group P4 $(81.7 \pm 7.8$ vs. $108.2 \pm 8.0 \mathrm{mmHg}$, $\mathrm{p}=0.02$ ). Bronchoaspiration or the PEEP change did not lead to a significant effect on these parameters; a decrease in MAP was observed only in Group P4 at 110 min (108 \pm 8 vs. 94.0 $\pm 7.0 \mathrm{mmHg}, \mathrm{p}=0.031)$.

\subsection{Gas exchange}

Arterial blood gas parameters are demonstrated in Table 1. No significant change was observed in arterial $\mathrm{pH}$ or $\mathrm{CO}_{2}$ throughout the study protocol in either group, except for a drop in $\mathrm{pH}$ in Group $\mathrm{P} 4$ following the change of PEEP $(\mathrm{p}=0.04)$, and an elevation in arterial $\mathrm{CO}_{2}$ in Group P10 at 110 min $(\mathrm{p}=0.016)$. A significant decrement was detected in HQ for both groups at $20 \min (\mathrm{p}=0.048$ and $\mathrm{p}=0.020$ for Group P10 and Group P4, respectively), but no change was apparent thereafter. 


\section{DISCUSSION}

In the present study changes in the lung mechanical and ventilation properties were measured for the left and right lungs separately following unilateral gastric juice aspiration. This approach allowed a within-subject comparison of the local and indirect systemic effects of the bronchoaspiration by measuring the affected and the intact lung separetely. Our results revealed that the marked acute lung mechanical responses observed in the airway and tissue mechanical properties in the aspirated lung were not associated with any detectable deterioration on the intact side at the 2-h follow-up after aspiration. Nevertheless, there was a significant association between the magnitude of the airway response in the intact lung and that in the aspirated lung. The presence of an uneven ventilation of the aspirated lungs was obvious from the values of the elevated normalized capnogram third phase slope. However, this change was not seen in the intact lung, in accordance with the forced oscillatory mechanical findings. The elevation of the PEEP under these conditions prevented the adverse changes in the capnogram third phase slope, while it had only minor effects on the other lung mechanical, ventilation or oxygenation indices.

In agreement with the findings of the few previous studies in which the mechanical changes were assessed for both lungs together in various animal models, we observed an acute deterioration in the lung tissue mechanics in the aspirated lung (Ko et al., 2008; Meers et al., 2011; Petak et al., 1998). This adverse change can be attributed to pulmonary oedema due to the increased vascular permeability (Goldman et al., 1993; Grimbert et al., 1981; Ko et al., 2008), surfactant dysfunction (Davidson et al., 2005; Lamonica et al., 2014) and inflammation (Knight et al., 1992; Nader-Djalal et al., 2007). Since all of these processes promote the development of atelectasis leading to a lung volume loss, the elevations in the unilateral $\mathrm{G}$ and $\mathrm{H}$ in the aspirated lungs are likely to occur subsequently to this phenomenon. The scarce 
earlier results indicated similar detrimental changes in the total resistive properties of the pulmonary system (Kuckelt et al., 1979; Meers et al., 2011; Tuchman et al., 1984). However, we are unaware of any previous studies assessing changes in airway mechanics following acid aspiration. The marked acute rise in Raw indicates the development of a transient bronchial smooth muscle contraction in the aspirated lung. Although the mechanisms responsible for this finding have not been fully clarified, it may be explained by the direct effect of the epithelial damage on the airway smooth muscle contractility (Gallos et al., 2013), or by the localized release of bronchoconstrictive neurotransmitters, such as tachykinin and bradykinin by capsaicin-sensitive neurons (Ricciardolo et al., 1999).

Respiratory abnormalities were also assessed in the present study by measuring $\mathrm{S}_{\mathrm{III}}$ and $\mathrm{Sn}_{\mathrm{III}}$. The extent of emptying of lung compartments containing various $\mathrm{CO}_{2}$ concentrations during mechanical ventilation and the shape of the resulting capnogram are determined primarily by the airway geometry (Blanch et al., 1999; Bohm et al., 2009; Nik Hisamuddin et al., 2009; Stromberg and Gustafsson, 2000; Yaron et al., 1996), and the driving pressure exerted by the elastic recoil of the respiratory tissues (Babik et al., 2012). The marked elevations in these parameters in the aspirated lungs suggest the presence of uneven lung ventilation, particularly at the lower PEEP level (Fig. 5). This may be subsequent to the localized deposition of the instilled gastric juice (Amigoni et al., 2008; Meers et al., 2011), which compromised the regional ventilation in these patchy lung areas.

Our findings also demonstrate the transient feature of this disturbance, since the ventilation abnormalities were no longer detectable $60 \mathrm{~min}$ after the aspiration. This temporal pattern suggests that the period $0-60 \mathrm{~min}$ is the optimum time window for the therapeutic application 
of an elevated PEEP against lung peripheral ventilation abnormalities following bronchoaspiration.

An elevation of the PEEP is commonly used to prevent persistent atelectasis formation following aspiration. Our results demonstrate no major benefit of this manoeuvre on either the airway or the lung tissue mechanics (Fig. 3). This finding agrees with previous results where no beneficial effect of a PEEP rise on the respiratory compliance was demonstrated following acid aspiration (Ko et al., 2008). However, the lack of an increase in $\mathrm{S}_{\mathrm{III}}$ in Group P10 indicates that the elevated PEEP prevented the development of ventilation defects in the lung periphery. This benefit was not associated with detrimental changes in the systemic haemodynamics or gas exchange. Indeed, compromised systemic haemodynamic changes have been reported only at higher PEEP levels, such as $15 \mathrm{cmH}_{2} \mathrm{O}$ (Marumo et al., 2009). This finding indicates that a moderately elevated PEEP has a beneficial effect on the aspiration-induced ventilation defects without affecting the systemic haemodynamics.

The most noteworthy finding of the present study is the experimental evidence that all these detrimental changes in the lung mechanics and ventilation were markedly repressed on the intact lung side, i.e. bronchoconstriction was detected only in the animals that responded strongly to unilateral aspiration (Fig. 4). This finding can be interpreted as it reveals a link between direct and indirect mechanisms by demonstrating the occasional presence of bronchoconstriction in the intact lung only if the bronchospasm was severe in the affected lungs. Overall, the markedly smaller responses in the intact lungs reflect the negligible role of the indirect constrictor mechanisms of systemic origin. However, it is also possible that the lack of change in the intact lungs following aspiration may result from the opposing effects of the elevated vagal tone leading to lung constriction (Kollarik et al., 2007; Nemzek and Kim, 
2009) and the endogenous release of catecholamines with relaxation potentials (Coupe et al., 1987). Independently of the mechanism, our data indicate the predominance of local effects over systemic effects in the aspiration-induced deterioration of lung function.

Our observations agree with those of previous studies, where local effects prevailed in the early stage of aspiration (the first 4-6 h) (Kennedy et al., 1989). Mechanisms proposed to explain this local damage include the direct corrosive effect of the aspirated gastric content (Wynne et al., 1981), the localized acute airway inflammation caused by the pepsin in gastric juice (Bathoorn et al., 2011), the localized release of bronchoactive mediators and the subsequent injury of the alveolar epithelium (Amigoni et al., 2008). Earlier studies pointed to the systemic effects predominating in the later stages (Schreiber et al., 2006); these are related mainly to inflammatory mechanisms, such as the activation of neutrophils (Motosugi et al., 1998; Weiser et al., 1997) or alveolar macrophages.

A number of methodological issues relating to the present experimental model warrant consideration. The model applied in the present study mimics the most important clinical features of bronchoaspiration, such as bronchospasm and atelectasis development leading to impaired oxygenation. However, the effects of aspiration on the lung oxygenation and on the systemic haemodynamics in the present study were less severe in magnitude than those obtained earlier (Meers et al., 2011). A plausible explanation for this apparent discrepancy may be the unilateral aspiration applied in the current experiments. This approach left one of the lungs intact, which ensured low mortality with relatively mild systemic consequences, similarly as with previously described models where unilateral acid aspiration was applied, but without assessing the functional changes in the lung in the aspirated and intact lungs individually (Amigoni et al., 2008; Schreiber et al., 2006). 
A further methodological issue relates to the ventilation mode involved in our porcine model. To maintain the minute ventilation following aspiration, the volume-controlled mode was selected. However, this mode of mechanical ventilation may lead to a mild overinflation of the intact lungs following unilateral aspiration via a redistribution of the pre-set tidal volume (Amigoni et al., 2013), especially when a relatively high PEEP is applied. This phenomenon may provide a plausible explanation for the significant lowering of Raw, $\mathrm{G}$ and $\mathrm{H}$ in Group P10 after 60 min on the intact lung side (Figs. 2 and 3).

Another technical aspect of our experiments is related to the measurement of pulmonary mechanical parameters in the open chest without the potential confounding effects of the chest wall mechanics. Configurational differences of the lungs in the intact and open-chest may have affected the values of the airway and tissue mechanical parameters (Petak et al., 1998) and haemodynamics (Hoit et al., 1997). However, this condition was stable throughout the study protocol and the mechanical parameters were obtained during small-amplitude oscillations that minimizes the mechanical stress and thus, these factors were not likely to affect our major findings. The use of a single-compartment model to estimate airway and tissue mechanical properties may have further limitation in case of development of ventilation heterogeneities (Lutchen et al., 1996), which is expected to occur in the affected lungs following bronchoaspiration. In this case, the increases in $G$ may overestimate the real changes in the parenchymal viscoelasticity due to the involvement of an artefactual component related to enhanced ventilation inhomogeneities.

In summary, we have developed an animal model with which to distinguish the local and the systemic effects of bronchoaspiration. Our study has provided experimental evidence that 
unilateral aspiration of the gastric contents leads to a unilateral lung injury in the first $2 \mathrm{~h}$, characterized by acute elevations of the airway and tissue mechanical and capnogram third phase slope parameters, but exclusively on the affected side. This indicates the primary need for treatment of the local detrimental consequences of bronchoaspiration in the acute phase (the first $2 \mathrm{~h}$ ) rather than targeting the adverse systemic changes. Application of a moderately high PEEP prevented the adverse changes in the third phase slope of the capnogram, indicating decreased ventilation heterogeneities. This benefit was not associated with changes in other mechanical, cardiovascular or lung oxygenation indices, suggesting that a moderately high PEEP may be beneficial in the optimum lung management following bronchoaspiration. 


\section{ACKNOWLEDGEMENTS}

The study was supported by a Hungarian Scientific Research Grant (OTKA K81179).

This research was supported by the European Union and the State of Hungary, co-financed by the European Social Fund in the framework of TÁMOP 4.2.4.A/2-11-1-2012-0001 'National Excellence Program' and 4.2.2.A-11/1/KONV-2012-0052.

The authors thank József Kaszaki for his excellent advice and Gabriella Varga for her invaluable assistance during the experiments.

The authors are grateful to Katalin Virág for the statistical advices. 


\section{REFERENCES}

Amigoni, M., Bellani, G., Scanziani, M., Masson, S., Bertoli, E., Radaelli, E., Patroniti, N., Di Lelio, A., Pesenti, A., Latini, R., 2008. Lung injury and recovery in a murine model of unilateral acid aspiration: functional, biochemical, and morphologic characterization. Anesthesiology 108, 1037-1046.

Amigoni, M., Bellani, G., Zambelli, V., Scanziani, M., Farina, F., Fagnani, L., Latini, R., Fumagalli, R., Pesenti, A., 2013. Unilateral acid aspiration augments the effects of ventilator lung injury in the contralateral lung. Anesthesiology 119, 642-651.

Babik, B., Csorba, Z., Czovek, D., Mayr, P.N., Bogats, G., Petak, F., 2012. Effects of respiratory mechanics on the capnogram phases: importance of dynamic compliance of the respiratory system. Crit Care 16, R177.

Bathoorn, E., Daly, P., Gaiser, B., Sternad, K., Poland, C., Macnee, W., Drost, E.M., 2011. Cytotoxicity and induction of inflammation by pepsin in Acid in bronchial epithelial cells. Int J Inflam 2011, 569416.

Blanch, L., Lucangelo, U., Lopez-Aguilar, J., Fernandez, R., Romero, P.V., 1999. Volumetric capnography in patients with acute lung injury: effects of positive end-expiratory pressure. Eur Respir J 13, 1048-1054.

Bohm, S.H., Maisch, S., von Sandersleben, A., Thamm, O., Passoni, I., Martinez Arca, J., Tusman, G., 2009. The effects of lung recruitment on the Phase III slope of volumetric capnography in morbidly obese patients. Anesth Analg 109, 151-159.

Cameron, J.L., Mitchell, W.H., Zuidema, G.D., 1973. Aspiration pneumonia. Clinical outcome following documented aspiration. Arch Surg 106, 49-52.

Colmenero-Ruiz, M., Fernandez-Mondejar, E., Fernandez-Sacristan, M.A., Rivera-Fernandez, R., Vazquez-Mata, G., 1997. PEEP and low tidal volume ventilation reduce lung water in porcine pulmonary edema. Am J Respir Crit Care Med 155, 964-970. 
Coupe, M.O., Guly, U., Brown, E., Barnes, P.J., 1987. Nebulised adrenaline in acute severe asthma: comparison with salbutamol. Eur J Respir Dis 71, 227-232.

Davidson, B.A., Knight, P.R., Wang, Z., Chess, P.R., Holm, B.A., Russo, T.A., Hutson, A., Notter, R.H., 2005. Surfactant alterations in acute inflammatory lung injury from aspiration of acid and gastric particulates. Am J Physiol Lung Cell Mol Physiol 288, L699-708.

Engelhardt, T., Webster, N.R., 1999. Pulmonary aspiration of gastric contents in anaesthesia. Br J Anaesth 83, 453-460.

Gallos, G., Townsend, E., Yim, P., Virag, L., Zhang, Y., Xu, D., Bacchetta, M., Emala, C.W., 2013. Airway epithelium is a predominant source of endogenous airway GABA and contributes to relaxation of airway smooth muscle tone. Am J Physiol Lung Cell Mol Physiol 304, L191-197.

Goldman, G., Welbourn, R., Klausner, J.M., Kobzik, L., Valeri, C.R., Shepro, D., Hechtman, H.B., 1991. Neutrophil accumulations due to pulmonary thromboxane synthesis mediate acid aspiration injury. J Appl Physiol 70, 1511-1517.

Goldman, G., Welbourn, R., Klausner, J.M., Kobzik, L., Valeri, C.R., Shepro, D., Hechtman, H.B., 1993. Leukocytes mediate acid aspiration-induced multiorgan edema. Surgery $114,13-20$.

Grimbert, F.A., Parker, J.C., Taylor, A.E., 1981. Increased pulmonary vascular permeability following acid aspiration. J Appl Physiol 51, 335-345.

Hantos, Z., Daroczy, B., Suki, B., Nagy, S., Fredberg, J.J., 1992. Input impedance and peripheral inhomogeneity of dog lungs. J Appl Physiol 72, 168-178.

Hoit, B.D., Ball, N., Walsh, R.A., 1997. Invasive hemodynamics and force-frequency relationships in open- versus closed-chest mice. Am J Physiol 273, H2528-2533. 
Kennedy, T.P., Johnson, K.J., Kunkel, R.G., Ward, P.A., Knight, P.R., Finch, J.S., 1989. Acute acid aspiration lung injury in the rat: biphasic pathogenesis. Anesth Analg 69, 87-92.

Knight, P.R., Druskovich, G., Tait, A.R., Johnson, K.J., 1992. The role of neutrophils, oxidants, and proteases in the pathogenesis of acid pulmonary injury. Anesthesiology $77,772-778$.

Ko, S.C., Zhang, H., Haitsma, J.J., Cheng, K.C., Li, C.F., Slutsky, A.S., 2008. Effects of PEEP levels following repeated recruitment maneuvers on ventilator-induced lung injury. Acta Anaesthesiol Scand 52, 514-521.

Kollarik, M., Ru, F., Undem, B.J., 2007. Acid-sensitive vagal sensory pathways and cough. Pulm Pharmacol Ther 20, 402-411.

Kuckelt, W., Dauberschmidt, R., Bender, V., Hieronymi, U., Mrochen, H., Winsel, K., Althaus, P., Meyer, M., 1979. Gas exchange, pulmonary mechanics and haemodynamics in adult respiratory distress syndrome: experimental results in Lewe miniature pigs. Resuscitation 7, 13-33.

Lamonica, G., Amigoni, M., Vedovelli, L., Zambelli, V., Scanziani, M., Bellani, G., Grassi, A., Simonato, M., Carnielli, V.P., Cogo, P.E., 2014. Pulmonary surfactant synthesis after unilateral lung injury in mice. J Appl Physiol (1985) 116, 210-215.

LeFrock, J.L., Clark, T.S., Davies, B., Klainer, A.S., 1979. Aspiration pneumonia: a ten-year review. Am Surg 45, 305-313.

Lutchen, K.R., Hantos, Z., Petak, F., Adamicza, A., Suki, B., 1996. Airway inhomogeneities contribute to apparent lung tissue mechanics during constriction. J Appl Physiol 80, 1841-1849.

Marik, P.E., 2001. Aspiration pneumonitis and aspiration pneumonia. N Engl J Med 344, 665671. 
Marik, P.E., 2011. Pulmonary aspiration syndromes. Curr Opin Pulm Med 17, 148-154.

Martling, C.R., Lundberg, J.M., 1988. Capsaicin sensitive afferents contribute to acute airway edema following tracheal instillation of hydrochloric acid or gastric juice in the rat. Anesthesiology 68, 350-356.

Marumo, C.K., Otsuki, D.A., Fantoni, D.T., Margarido, C.B., Ambrosio, A.M., Pelosi, P., Auler, J.O., Jr., 2009. Hemodynamic effects of PEEP in a porcine model of HClinduced mild acute lung injury. Acta Anaesthesiol Scand 53, 190-202.

Meers, C.M., De Wever, W., Verbeken, E., Mertens, V., Wauters, S., De Vleeschauwer, S.I., Vos, R., Vanaudenaerde, B.M., Verleden, G.M., Van Raemdonck, D.E., 2011. A porcine model of acute lung injury by instillation of gastric fluid. J Surg Res 166, e195-204.

Mendelson, C.L., 1946. The aspiration of stomach contents into the lungs during obstetric anesthesia. Am J Obstet Gynecol 52, 191-205.

Motosugi, H., Quinlan, W.M., Bree, M., Doerschuk, C.M., 1998. Role of CD11b in focal acid-induced pneumonia and contralateral lung injury in rats. Am J Respir Crit Care Med 157, 192-198.

Nader-Djalal, N., McQuiller, P.S., Raghavendran, K., Spengler, R.N., Knight, P.R., 2007. The role of alveolar macrophages in the pathogenesis of aspiration pneumonitis. Immunol Invest $36,457-471$.

Nemzek, J.A., Kim, J., 2009. Pulmonary inflammation and airway hyperresponsiveness in a mouse model of asthma complicated by acid aspiration. Comp Med 59, 321-330.

Nik Hisamuddin, N.A., Rashidi, A., Chew, K.S., Kamaruddin, J., Idzwan, Z., Teo, A.H., 2009. Correlations between capnographic waveforms and peak flow meter measurement in emergency department management of asthma. Int J Emerg Med 2, 83-89. 
Nishizawa, H., Yamada, H., Miyazaki, H., Ohara, M., Kaneko, K., Yamakawa, T., WienerKronish, J., 1996. Soluble Complement Receptor Type 1 Inhibited the Systemic Organ Injury Caused by Acid Instillation into a Lung. Anesthesiology 85, 11201128.

Olsson, G.L., Hallen, B., Hambraeus-Jonzon, K., 1986. Aspiration during anaesthesia: a computer-aided study of 185,358 anaesthetics. Acta Anaesthesiol Scand 30, 84-92.

Petak, F., Habre, W., Babik, B., Tolnai, J., Hantos, Z., 2006. Crackle-sound recording to monitor airway closure and recruitment in ventilated pigs. Eur Respir J 27, 808-816.

Petak, F., Hall, G.L., Sly, P.D., 1998. Repeated measurements of airway and parenchymal mechanics in rats by using low-frequency oscillations. J Appl Physiol (1985) 84, $1680-1686$.

Raghavendran, K., Nemzek, J., Napolitano, L.M., Knight, P.R., 2011. Aspiration-induced lung injury. Crit Care Med 39, 818-826.

Ricciardolo, F.L., Rado, V., Fabbri, L.M., Sterk, P.J., Di Maria, G.U., Geppetti, P., 1999. Bronchoconstriction induced by citric acid inhalation in guinea pigs: role of tachykinins, bradykinin, and nitric oxide. Am J Respir Crit Care Med 159, 557-562.

Schreiber, T., Hueter, L., Gaser, E., Schmidt, B., Schwarzkopf, K., Rek, H., Karzai, W., 2006. PEEP has beneficial effects on inflammation in the injured and no deleterious effects on the noninjured lung after unilateral lung acid instillation. Intensive Care Med 32, 740-749.

Stromberg, N.O., Gustafsson, P.M., 2000. Ventilation inhomogeneity assessed by nitrogen washout and ventilation-perfusion mismatch by capnography in stable and induced airway obstruction. Pediatr Pulmonol 29, 94-102. 
Tuchman, D.N., Boyle, J.T., Pack, A.I., Scwartz, J., Kokonos, M., Spitzer, A.R., Cohen, S., 1984. Comparison of airway responses following tracheal or esophageal acidification in the cat. Gastroenterology 87, 872-881.

Warner, M.A., Warner, M.E., Weber, J.G., 1993. Clinical significance of pulmonary aspiration during the perioperative period. Anesthesiology 78, 56-62.

Weiser, M.R., Pechet, T.T., Williams, J.P., Ma, M., Frenette, P.S., Moore, F.D., Kobzik, L., Hines, R.O., Wagner, D.D., Carroll, M.C., Hechtman, H.B., 1997. Experimental murine acid aspiration injury is mediated by neutrophils and the alternative complement pathway. J Appl Physiol 83, 1090-1095.

Wynne, J.W., Ramphal, R., Hood, C.I., 1981. Tracheal mucosal damage after aspiration. A scanning electron Microscope study. Am Rev Respir Dis 124, 728-732.

Yaron, M., Padyk, P., Hutsinpiller, M., Cairns, C.B., 1996. Utility of the expiratory capnogram in the assessment of bronchospasm. Ann Emerg Med 28, 403-407. 


\section{FIGURE LEGENDS}

Figure 1. Scheme of the experimental protocol. $\mathrm{Z}_{\mathrm{L}, \mathrm{s}}$ : unilateral pulmonary input impedance measurement. L/R: measurement of left or right lung. $\mathrm{PEEP}_{\mathrm{A}}$ and $\mathrm{PEEP}_{\mathrm{B}}$ correspond to 4 and $10 \mathrm{cmH}_{2} \mathrm{O}$, respectively, in random sequence.

Figure 2. Airway resistance (Raw), tissue damping $(\mathrm{G})$ and elastance $(\mathrm{H})$ for the acidic and the intact lungs in Groups P10 and P4 under baseline conditions ( 0 min) and following aspiration. *: $\mathrm{p}<0.05$ between acidic and intact lungs; \#: $\mathrm{p}<0.05$ vs. baseline conditions within the same lung.

Figure 3. Relative changes in airway resistance (Raw), tissue damping $(\mathrm{G})$ and elastance $(\mathrm{H})$ in response to bronchoaspiration at 5, 60, 90 and 120 min. *: p $<0.05$ between acidic and intact lungs; \#: $\mathrm{p}<0.05$ vs. baseline conditions within the same lung, $\S: \mathrm{p}<0.05$ vs. values at 5 min within the same lung.

Figure 4. Association between the changes in airway resistance in the acidic and the intact lung in the first 60 min following aspiration in Groups P4 and P10. Solid line: linear regression.

Figure 5. Third phase slope of the capnogram $\left(\mathrm{S}_{\mathrm{III}}\right)$ and its normalized value $\left(\mathrm{Sn}_{\mathrm{III}}\right)$ for the acidic and the intact lungs in Groups P10 and P4 under baseline conditions ( 0 min) and following aspiration. *: $\mathrm{p}<0.05$ between acidic and intact lungs; \#: $\mathrm{p}<0.05$ vs. baseline conditions within the same lung, $\S: \mathrm{p}<0.05$ vs. values at 5 min within the same lung. 


\begin{tabular}{lcccccc} 
& \multicolumn{2}{c}{ Arterial pH } & \multicolumn{2}{c}{$\mathrm{HQ}(\mathrm{mmHg})$} & \multicolumn{2}{c}{ Arterial $\mathrm{CO}_{2}(\mathrm{mmHg})$} \\
& Group P10 & Group P4 & Group P10 & Group P4 & Group P10 & Group P4 \\
& & & & & \\
\hline 0 min & $7.40 \pm 0.03$ & $7.43 \pm 0.02$ & $507 \pm 59$ & $475 \pm 19$ & $51.00 \pm 5.80$ & $49.90 \pm 4.67$ \\
& & & & & & \\
\hline $20 \mathrm{~min}$ & $7.34 \pm 0.04$ & $7.38 \pm 0.02 \#$ & $365 \pm 52 \#$ & $374 \pm 58 \#$ & $60.38 \pm 4.92$ & $56.06 \pm 4.77$ \\
\hline 80 min & $7.35 \pm 0.05$ & $7.35 \pm 0.02$ & $388 \pm 72$ & $472 \pm 16$ & $59.84 \pm 6.66$ & $60.60 \pm 2.97$ \\
\hline 110 min & $7.30 \pm 0.06$ & $7.36 \pm 0.02$ & $384 \pm 91$ & $494 \pm 23$ & $69.43 \pm 8.98 \#$ & $59.00 \pm 3.19$
\end{tabular}

Table 1: Arterial $\mathrm{pH}$, Horowitz-quotient $(\mathrm{HQ})$ and arterial partial $\mathrm{CO}_{2}$ pressure in Groups $\mathrm{P} 10$ and P4 under baseline conditions (0 min) and following aspiration. \#: p < 0.05 vs. baseline conditions within the same group. 


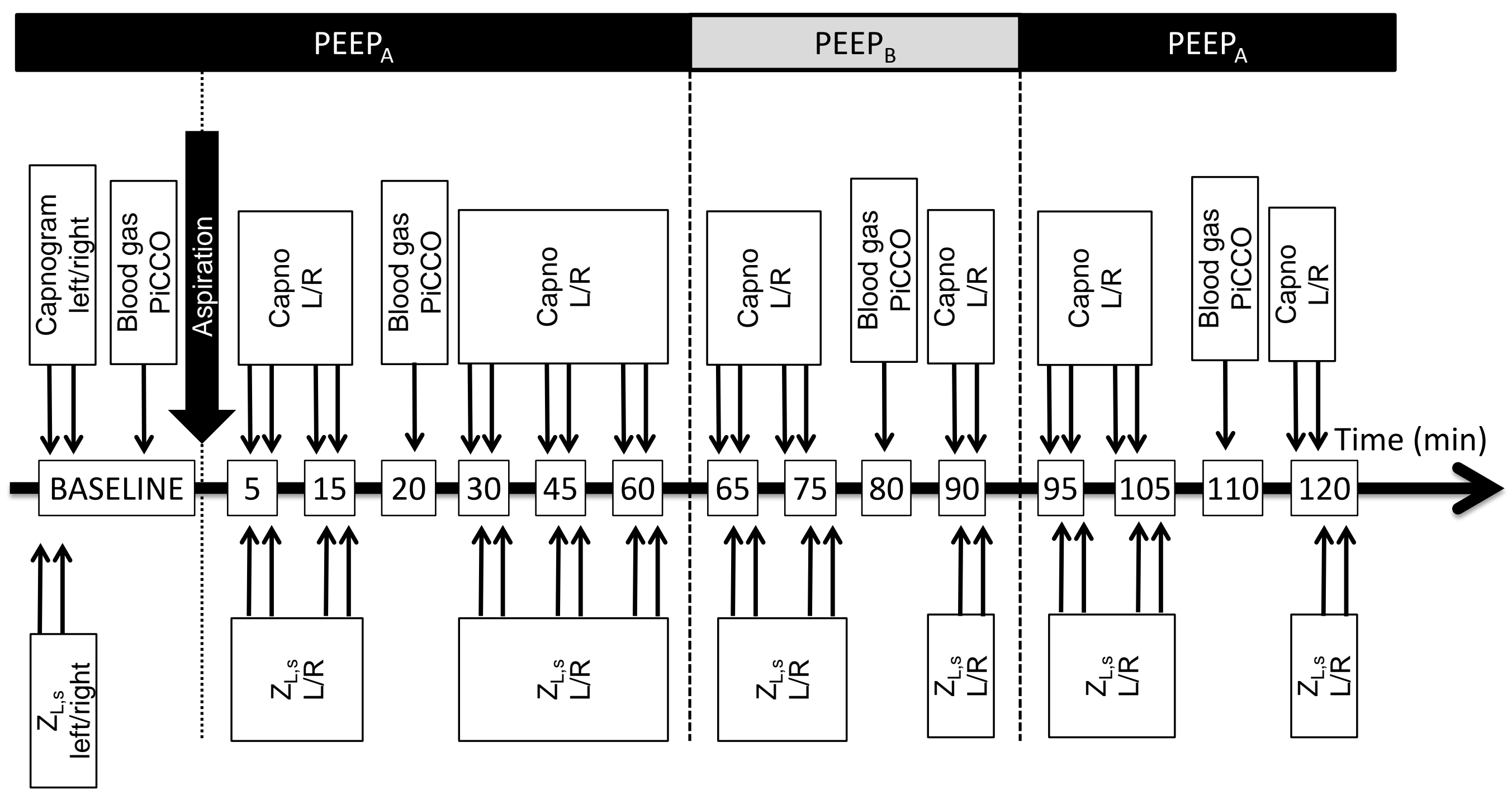

Figure 1 
GROUP P10
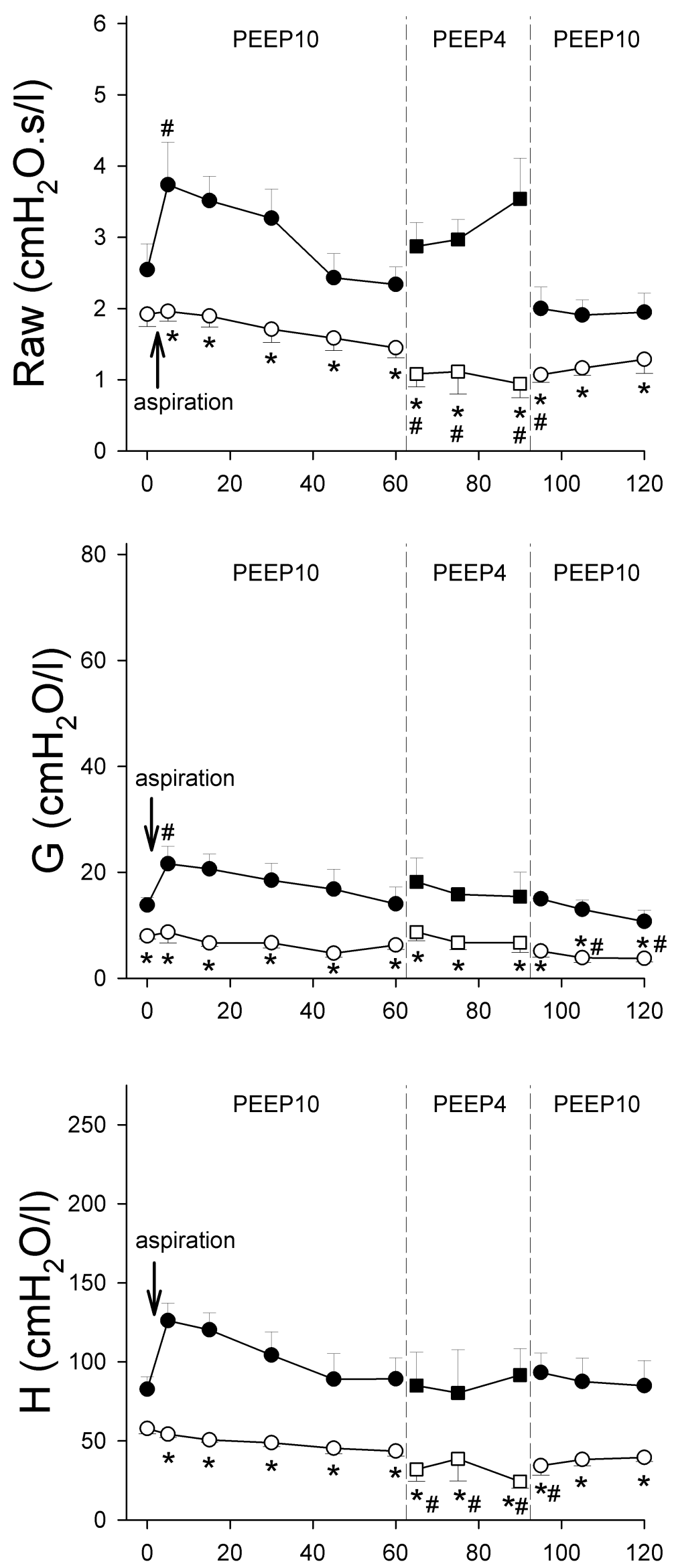

GROUP P4
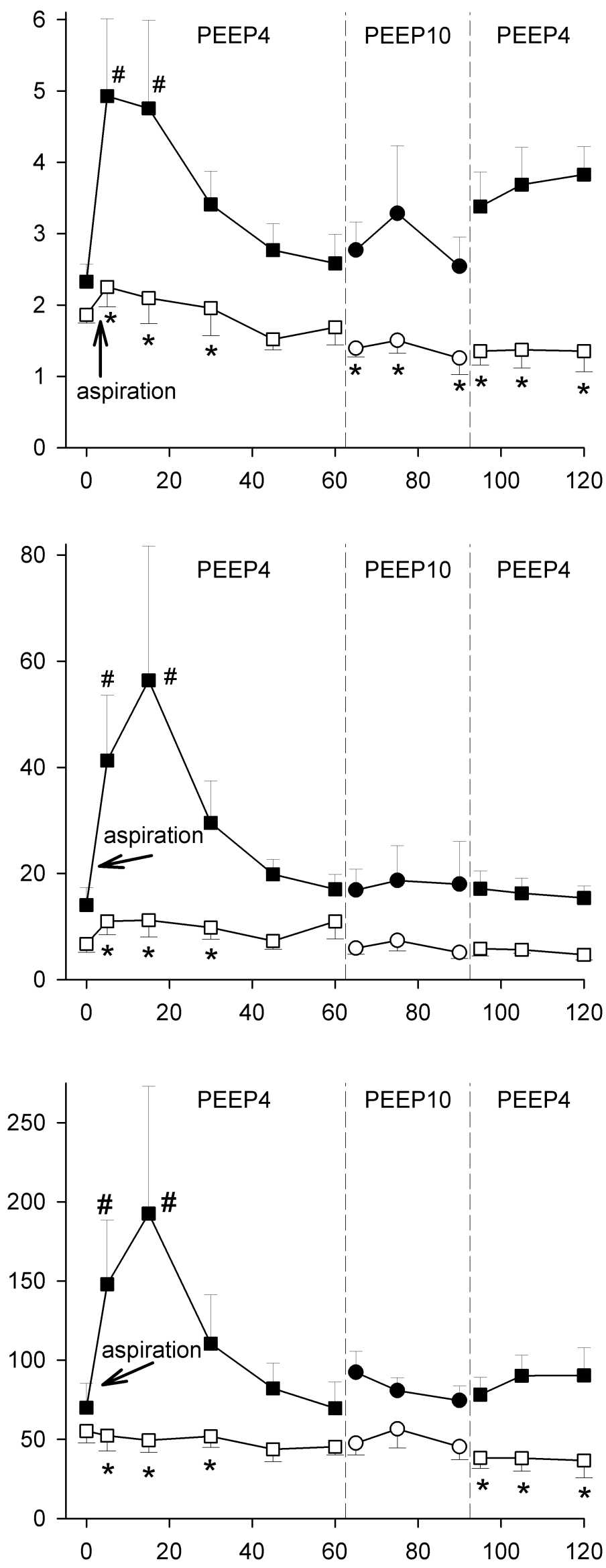

Time (min)

Figure 2 
GROUP P10

GROUP P4
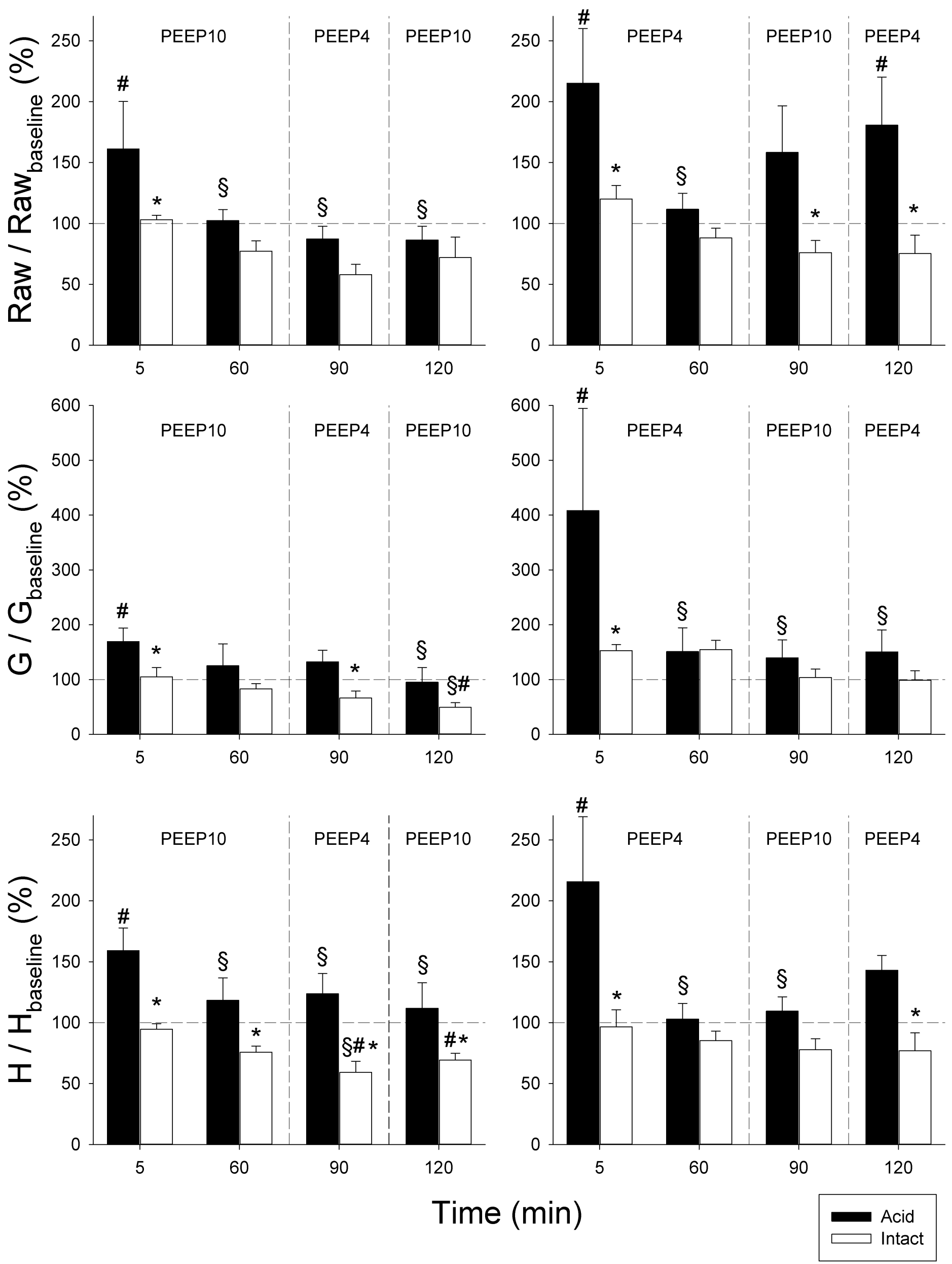

Figure 3 


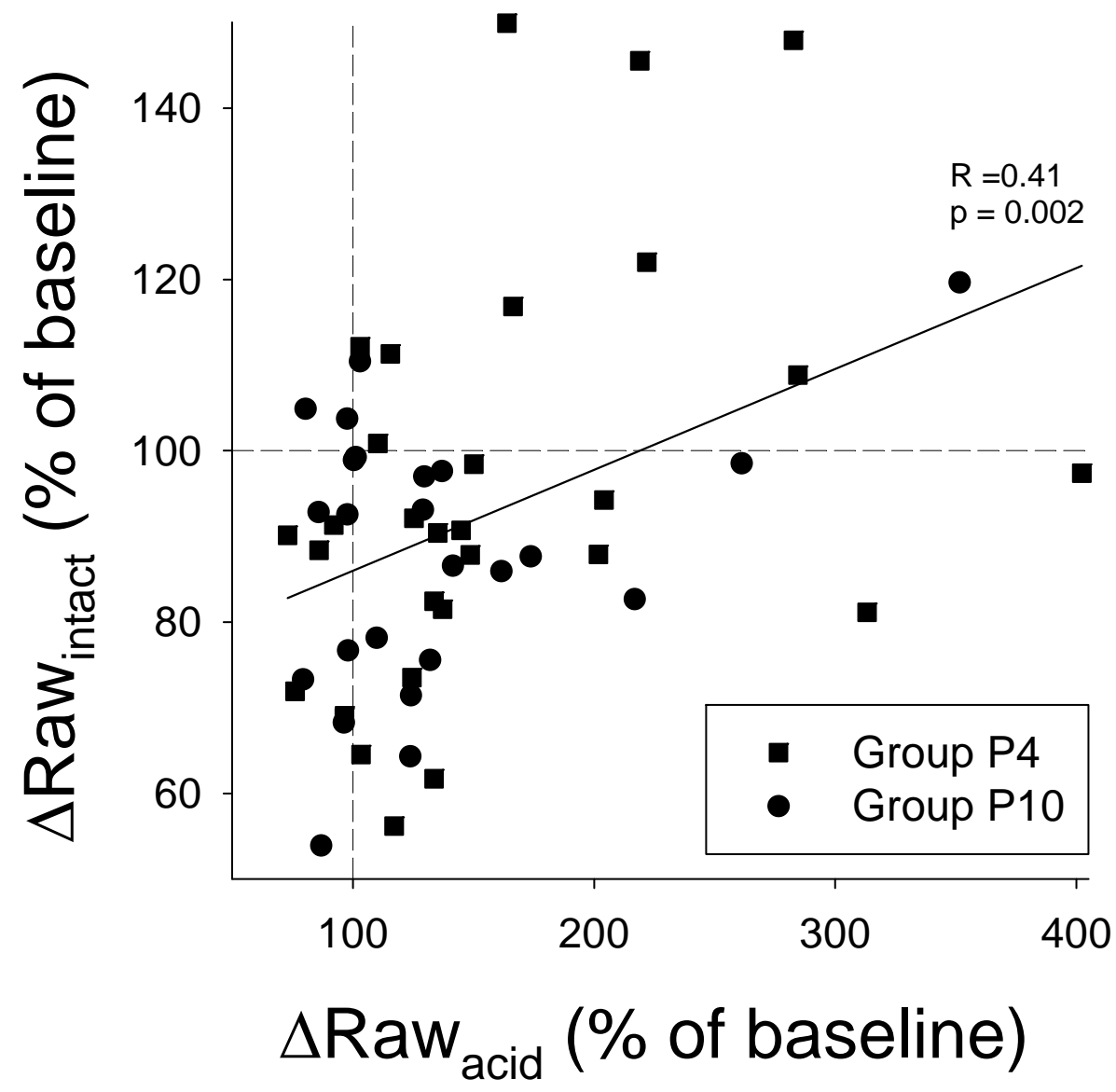

Figure 4 
GROUP P10
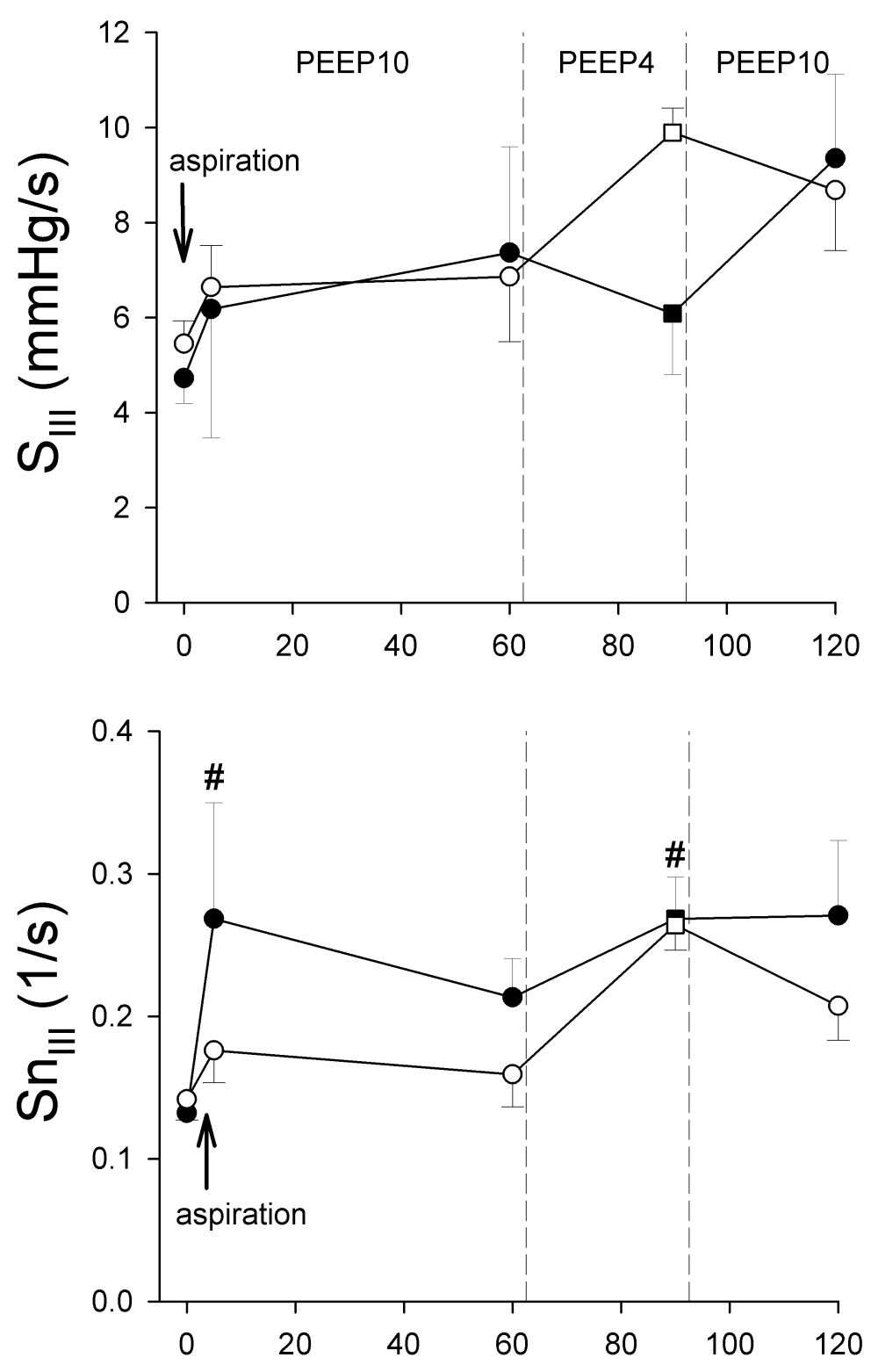

GROUP P4
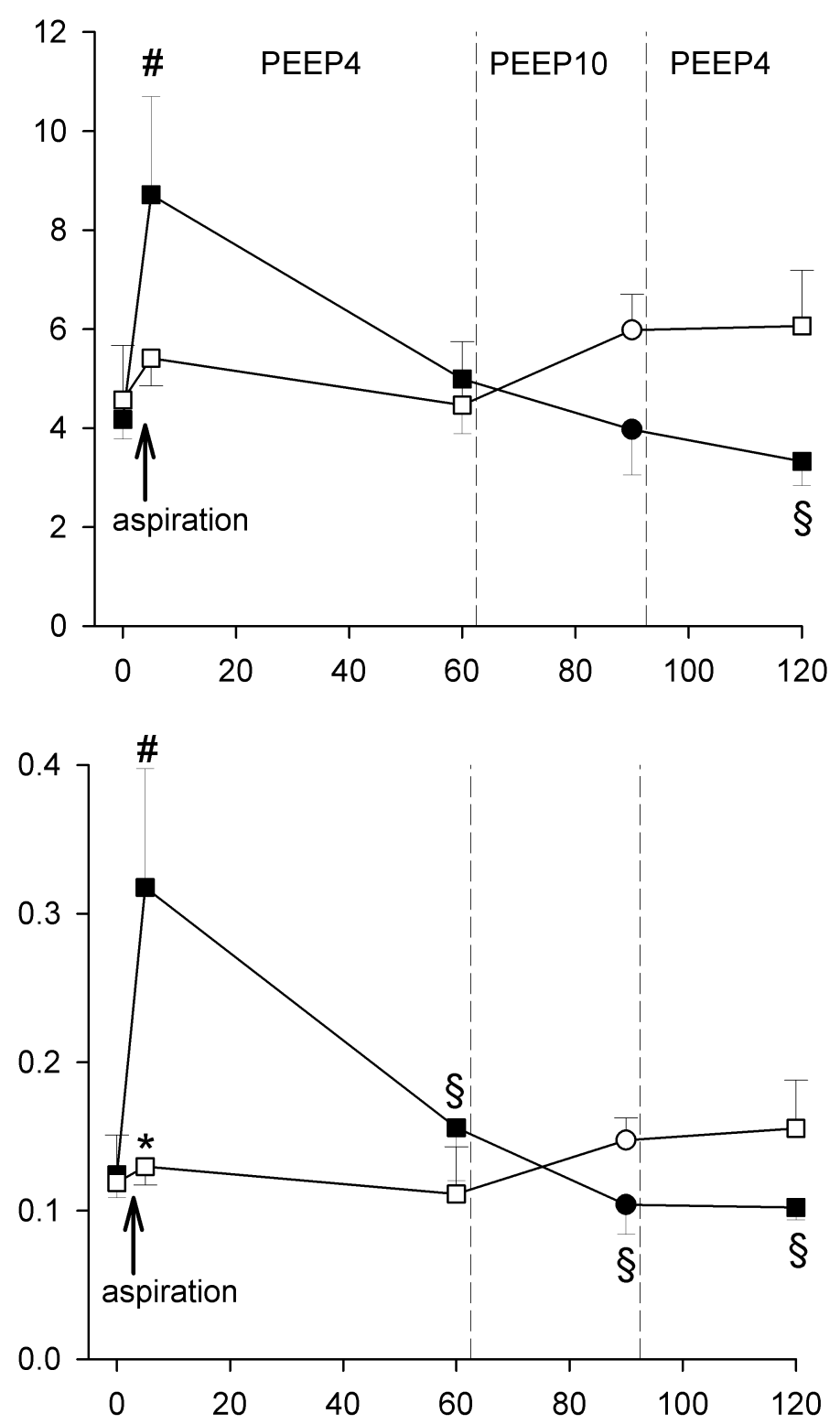

Time (min)

Figure 5 
Arterial $\mathrm{pH}$

HQ (mmHg)

Arterial $\mathrm{CO}_{2}(\mathrm{mmHg})$

Group P10 Group P4 Group P10 Group P4 Group P10 Group P4

\begin{tabular}{lllllll}
\hline $0 \min$ & $7.40 \pm 0.03$ & $7.43 \pm 0.02$ & $507 \pm 59$ & $475 \pm 19$ & $51.00 \pm 5.80$ & $49.90 \pm 4.67$
\end{tabular}

\begin{tabular}{lcccccc}
\hline $20 \min$ & $7.34 \pm 0.04$ & $7.38 \pm 0.02 \#$ & $365 \pm 52 \#$ & $374 \pm 58 \#$ & $60.38 \pm 4.92$ & $56.06 \pm 4.77$ \\
& & & & & & \\
\hline $80 \min$ & $7.35 \pm 0.05$ & $7.35 \pm 0.02$ & $388 \pm 72$ & $472 \pm 16$ & $59.84 \pm 6.66$ & $60.60 \pm 2.97$ \\
& & & & & & \\
\hline $110 \min$ & $7.30 \pm 0.06$ & $7.36 \pm 0.02$ & $384 \pm 91$ & $494 \pm 23$ & $69.43 \pm 8.98 \#$ & $59.00 \pm 3.19$
\end{tabular}

Table 1: Arterial pH, Horowitz-quotient (HQ) and arterial partial $\mathrm{CO}_{2}$ pressure in Groups $\mathrm{P} 10$ and P4 under baseline conditions (0 min) and following aspiration. \#: p $<0.05$ vs. baseline conditions within the same group. 